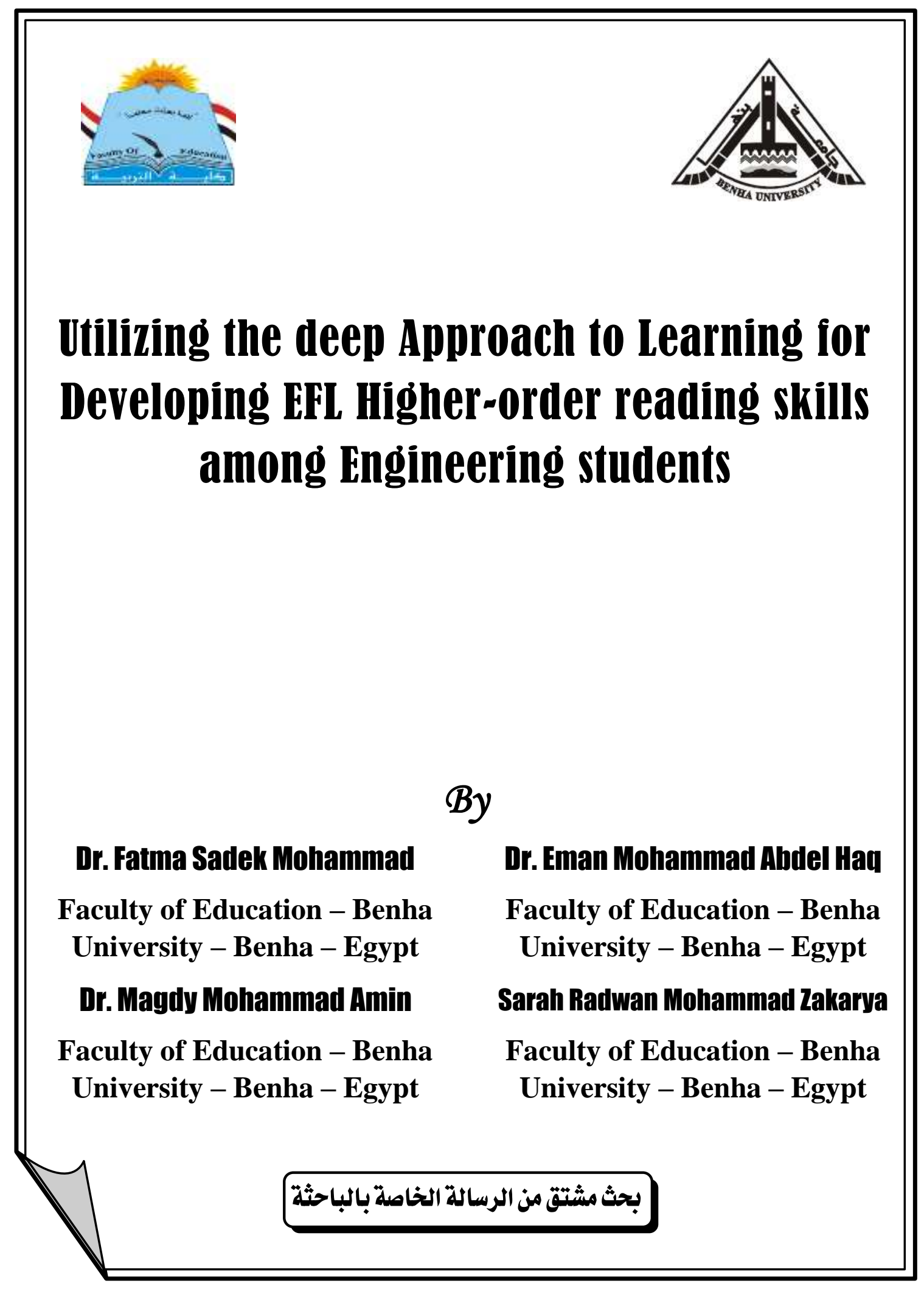




\section{Utilizing the deep Approach to Learning for Developing EFL Higher- order reading skills among Engineering students}

\section{By}

Dr. Fatma Sadek Mohammad

Faculty of Education - Benha

University - Benha - Egypt

\section{Dr. Magdy Mohammad Amin}

Faculty of Education - Benha University - Benha - Egypt
Dr. Eman Mohammad Ahdel Hay

Faculty of Education - Benha

University - Benha - Egypt

\section{Sarah Radwan Mohammad Zakaryz}

Faculty of Education - Benha University - Benha - Egypt

\section{Ahstract}

Academic reading skills are very vital for university students. This paper aimed at investigating the role of the deep approach to learning in utilizing English ESP higher-order reading skills among engineering students. Sixty three participants from first year students at Benha Faculty of Engineering were randomly assigned into two groups: an experimental group ( $n=33)$ and a control group $(n=30)$. Two main instruments were used: an academic reading pre-test, and an academic reading post-test. Quantitative data analyses were conducted. Using T-test to compare the mean scores of the control group and the experimental group in the pre-post application. Results showed that the experimental group students have developed their EFL higher-order reading skills. It was concluded that the "the deep approach to learning" was effective in utilizing ESP higher-order reading skills of the participants. It was also recommended that the deep approach to learning is very effective in developing language learning in general and in developing EFL higher-order reading skills in specific. The deep approach to learning should be integrated into ESP higher-order reading skills approachs.

Keywords: the deep approach to learning, ESP higher-order reading skills. 


\section{Introduction}

Reading is the basic way for acquiring information, learning and entertainment. The ability to read academic text is considered one of the most important skills that university students of English as a Foreign Language (EFL) need to acquire. It should be noted that for the most part reading instruction in the EFL university courses tends to focus on text processing, on the reader's understanding of the language of the text. (Levine, Ferenz \& Reves, 2000: 1)

Moreover, Noor (2006: 66) pointed out that in any academic or higher cognitive learning context, reading is perceived as the most prominent academic skill for university students. It is through reading that these learners will learn new information and are able to synthesize, evaluate and interpret the context and reconstruct it to learn more about their subject matter. Yet, most often, many students who enter institutions of higher learning are found to be unprepared for the reading demands placed upon them and they encounter difficulties. Factors such as low level proficiency of the English language, poor reading strategy knowledge, perceptions of reading and low interest are often mentioned by researchers as contributing to students' problems in approaching reading.

The present study intends to develop EFL cognitive academic skills which are vocabulary skills, coherence skills, author's stance skills, perception and automatic recognition skills, higher-order reading skills, and meta-skills among the study subjects through using the deep approach to learning.

\section{Review of Literature and Related Studies}

Tam (1999) stated that "There is a need for education today to move away from an emphasis upon teaching towards a perspective which emphasizes learning. "This orientation, often referred to as 'learner centeredness' provides a conceptual framework for describing 
how a learner defines his or her world of learning and comes to terms with it by engaging in the process of learning he or she finds relevant to personal goals and interests. Students bring into the learning system some predispositions that are learning related, such as prior knowledge, abilities values and expectations, ways of learning. Hence, an approach to learning is not simply a fixed attribute of the learner, but a function of both learner characteristics and the teaching factors. The student and teaching contexts when combined will produce a particular approach to learning which is broadly conceptualized as either 'deep' or 'surface'" (2).

Many researchers defined the deep approach as 'an intention to understand for oneself which brings into play the integration of ideas and using evidence and logic in reaching conclusions' that the surface approach is 'intention to pass without too much effort or thinking leads to inappropriate attempts to rote learn or to follow procedures blindly.

Cope (2003, 424), Lublin (2003, 3), and Smith $(2005,6)$ identified the characteristics of students' deep approach to learning as follows: intent to seek a deep understanding of the subject; interact vigorously with the content; make use of evidence, inquiry and evaluation; take a broad view and relate ideas to one another; are motivated by interest; relate new ideas to previous knowledge; relate concepts to everyday experience; tend to read and study beyond the course requirements; and be aware of one's own understanding of the concept of the subject and the approaches being used to learn about it.

Moreover, Millis $(2002,2)$, and Mohanna $(2008,24)$ identified the characteristics of teaching and key components that could foster a deep approach to learning as follows. (1) motivational content: who owns the agenda of the teaching. Students learn best when they understand the importance of what they are learning and are involved in selecting what is learnt and planning how this learning will take place. (2) learner activity: 
active participation enables links to be made between new concepts and past learning. Activity alone however is insufficient. It must be planned, reflected upon, processed and integrated with abstract concepts (the learning cycle); interaction with others. It can be easier to negotiate meaning and to manipulate ideas with others than alone. (3) wellstructured knowledge base. If a student is to integrate new learning with previous knowledge there must be order and structure to the learning.

The deep approach goes through 3 stages, the presage factors (student based - teaching context based) interact at the process level to determine the students' immediate learning- related activities, as approaches to learning. The common goal here is learning, and the immediate system comprises all things in and out of the classroom that might affect each other and thus the outcomes. Systems are interactive, not linear. Collectively, these background factors determine the cognitive processes the students are likely to use, which in turn determine the detail and structure inherent in the learning outcomes, and how the students feel about the outcome (Biggs, 2003, 19).

Moreover, the deep approach to world language aims to stimulate action projects in language learning that are in touch with real life, culture, and society. This approach moves holistically towards language integration into world- or life-related thematic projects and requires contextualized, holistic experiences in which the personal identity narrative can expand with new life meaning (Xiao, 2015: 489). Deep linguistics or transformational linguistics use language powerfully to change learners at the deepest level through suggestion and altere states of consciousness. In this respect, the issue for the teacher and the educator is very similar to issues raised by taxonomies of socio-effective goals: as long as the learners are free to choose their own goals and are made aware of the approach; they can keep their autonomy. Critical distance is welcome in a deep approach as what is underlying it is the concept of empowerment (Tochon, 2010: 7). 
"There are four principles of deep language learning: pedagogy is a language of practice as students should plan their learning, and as they work to realize their projects: (1) reflexive learning adapts itself to students projects as reflexive apprenticeship represents a dynamic process: students reflect in the moment and make decisions for projects that play a mediating role in the apprenticeship of the language; deep teaching requires flexible planning: learning is a negotiated process that gives a sense to the resources in organizing them in educational projects relatable for material's integration. (2) deep learning is reflective and does not require a normative framework: deep, reflective teaching is an open form of scaffolding and feedback centered on the process of learning. The goal is autonomous, creative reflection and action while developing proficiency" (Tochon, 2014: 34).

The advantages of deep approach to world languages and cultures are: (1) understand how self-motivation and attitude could be the best incentive for deep language learning. (2) provide themes, motives, templates and incentives for self-directed learning and selfdetermination. (3) empower the students to be the curriculum builder by scaffolding possibilities and making instruction flexible. (4) emphasize the learning process rather than pre-determined outcomes. (5) encourage individualized, peer-oriented, and project-based learning by focusing on cultural contents. (6) value creation and social action. (7) consider grammar as story-telling about language; use formative, deep evaluation of integrated skills. (8) focus on value creation: highlight critical issues related to the aspect of culture, language statues and discrimination (Tochon, 2014, 17 and Xiao, 2015, 491). 
The following conclusions can be drawn, based on the related studies as follows:

Language leaning tasks have cross-cultural purposes which then become meaningful within broader projects that meet higher values and aims such as deep ecology, deep culture, deep politics, and deep human economics. It increases the sense of responsibility for all actions (Xiao, 2015). The way language approachs shape the lives of teachers and the life of language learners is puzzling when considered from the perspective of the need for more autonomy to increase learners' motivation and approach effectiveness (Tochon, 2014).

Designing curriculum and learning experiences that enable preservice teachers to apply their knowledge constantly within discipline contexts, such as linguistics, will support deep knowledge within those units that do not have immediate links to using theory in practice (Fenwick \& et al., 2013).

Deep approach to language learning represents a new orientation and an important contribution to less commonly taught language teaching and learning, as this is a field in which textbooks are rare and sometimes obsolete (Tochon, 2013). teachers' thinking and motivation related to professional learning and instructional processes is a key consideration in successful educational systems. The relation between teachers' motivation levels and improved foreign language learning has been underscored by Karaman, Ökten, and Tochon (2012).

On the other hand, Academic reading is a complex, multi-level and different from other kinds of reading. So, it is a purposeful and critical reading of a range of lengthy academic texts for completing the study of specific major subject area. Academic reading requires: both extensive and intensive reading of texts that are discipline- specific, careful synthesizing of a material from a number of sources, and 
consciously finding authorial intentions and purpose (Sengupta, 2002: 3 ). Academic reading is different because there is an enormous amount of specialist materials which contain challenging vocabulary and concepts that is un familiar to students to read in a short time. Moreover, Hermida (2009) stated that 'reading an academic text doesn't simply involve finding information on the text itself. Rather, it is a process of working with the text. When reading an academic text, the reader recreates the meaning of the text, together with the author" (23).

According to Alyousef (2005), Mohd. (2006), and Hellekjær (2009), academic reading importance are concluded as follows: learners can build knowledge of language which will facilitate reading ability; build schematic knowledge; have the ability to adapt the reading style according to reading purpose; develop an awareness of the structure of written texts in English; learners can take a critical stance to the contents of the texts; in addition, they will learn new information and are able to synthesize, evaluate, and interpret to learn more about their subject matter. Academic reading it is the active creation of meaning in an interactive process between information in a text and the reader's knowledge.

Syatriana (2013) tried to find out whether cognitive reading strategy can develop the reading skills of the first year students of SMAN 16 Makassar in the academic year 2011/2012. The sample was 30 students using total sampling technique. The results of data analysis indicated achievement in reading comprehension. So, the researcher concluded that cognitive reading strategies were effective in developing the students' reading comprehension.

Based on the related studies of Alemi; and Ebadi (2010), Erfani; Iranmehr; and Davari (2011), Tabatabaei; and Assari (2011), and Rahman (2012), Aryusmar (2013) the following conclusions can be drawn: most students need help in moving from the state of dependence

\section{9}


on the instruction (teacher-centered learning) to become independent readers in the target language. This independence in reading can be achieved if students are first introduced to the techniques of reading, and second if they are given a real chance to practice these techniques and gain familiarity in their use. Students need to activate prior knowledge of the topic before they begin to read. If students do not have sufficient prior knowledge, they should be given at least minimal background information from which to interpret the text. ESP students should become aware of the importance of using different reading strategies while reading any kind of reading, including ESP readings. Teaching students to become constructively responsive readers can be a powerful way to promote skillful academic readings which will enhance academic achievement. Foreign language teaching practitioners as well as test makers can use the insights into ESP reading to facilitate their ESP instruction and to develop more reliable and valid ESP reading tests.

A deep approach to academic reading is an approach where the reader uses higher-order cognitive skills such as the ability to analyze, synthesize, solve problems, and thinks meta-cognitively in order to negotiate meanings with the author and to construct new meaning from the text. The deeper reader focuses on the author's message, on the ideas he/she is trying to convey, the line of argument, and the structure of the argument. The reader makes connections to already known concepts and principles and uses this understanding for problem solving in new contexts (Hermida, 2009, 21).

A student taking a deep approach reads widely, discusses with others, theorizes about the subjects, and relates what is learnt to personally meaningful contexts and / or existing prior knowledge. Students who are better in their language performance generally make frequent use of a greater number of reading strategies and process reading materials at a deep level for greater reading comprehension. As language proficiency develops, linguistic cues can be used more efficiently and that deep-level processing strategies such as inferencing, prediction and contextualization will operate more smoothly (Rao and et al., 200v, 246-249). 
Noor $(2007,5)$ sees that deep reading approach is characterized by: intrinsic motivation; interact actively with the text; using various strategies in identifying key words and main points; and identifying the link between paragraphs to understand what the text is about.

The categories of the deep approach to learning pertaining to academic reading are: the first is the intrinsic motivation of reading the text. The first: These deep readers were more concerned with the information or knowledge that they would gain from reading the text. They also attempted to assess how this information could be put to use for future purposes such as in their writing assignments. Hence, this would suggest that these readers' motivation of reading was for personal improvement rather expecting external rewards such getting good grades for examination. The second: strategy used is the advance organizers that they drew to help with organizing information leading to a better understanding of the linking between points and ideas (It was interesting to note that only the deep readers were discovered to utilize such frameworks in their readings). The third: the monitoring and evaluating of information as they read suggest that these subjects are applying strategies which include having a purpose in mind or using aids such as tables and figures to monitor their reading (These strategies have been considered to be vital for successful learning) (Noor, 2010, 34).

Hermida $(2009,27)$ set out some teaching and learning strategies that foster a deep approach to reading as follows: the apprentice: assign each group a journal article (Give teams reading guides to encourage them to evaluate, judge, compare, and synthesize information from texts); summarize and explain; concept mapping: students represent their understanding of a text by producing graphs which display the relationships between concepts and ideas; facebook or myspace profile: giving students an article and ask them to create a myspace type of profile about a topic of the article; and the movie studio: students need to read an article on a topic discussed in class, Then, they need to write a treatment for a documentary about the content of the article and pitch the idea for funding to executives from a film company. 
In their study, Rao and et al. (200v) identified deep-level processing strategies to reading as follows: 1- inferencing: guessing unknown meaning using prior knowledge and other relevant sources of knowledge. 2- prediction: anticipating what content will occur in succeeding portions of text. 3-contextualization: connecting new information with previously stated content. 4-global questioning of text: questioning the significance, coherence or veracity of content. 5recognition of text structure: distinguishing between main ideas and supporting details. 6-comprehension evaluation: noticing that an interpretation or paraphrase is incorrect and modifying comprehension. 7-summarization: summarizing the main ideas of a passage; appreciation of given text: appreciating what one is reading; and reconstruction: recognizing the content of a text to grasp the main idea (252).

Noor (2006) described the reading process of six second-year Bachelor of arts students, majoring in English Language studies. Results indicated that it is important that students are made aware of their reading approaches. The students who adopted a deep approach to learning would be involved in an active, transformative process of learning. Hence, they would develop a deep level of understanding. On the other hand, those who pursue a surface approach are highly likely to develop a superficial or incomplete level of understanding.

Noor (2007) describe and compared six learners' approaches of two readings of an academic expository text. Three instruments were used to collect data: reading tests, individual interviews and observations, whereby all sessions were videotaped, audio taped and transcribed verbatim. Findings of the study revealed that there were qualitative differences in the approaches of reading an academic expository text and that different types of approaches were employed in the two readings of the text. 
Hermida (2009) evaluated whether students took a deep or a surface approach to reading. The goal was to assess the quality of their learning outcome, as the approach to reading is considered to be directly proportional to the quality of their learning outcome. The subjects of the study were a group of first year university students in a Legal Studies course. Results showed that most University students adopt a surface approach to reading, but when teachers designed an aligned course that places academic reading at the forefront of the course, where the selected class activities encourage students to use higher order cognitive skills to construct meaning from academic texts, students tend to take a deep approach to reading and learning.

The purpose of Noor's (2010) study was to explore the reading approaches of learners reading an academic expository text. The sample of this study involved six second year Bachelor of Arts students, majoring in English Language Studies. Findings revealed variations that represented the deep and surface approaches of reading an academic expository text.

In their study, Chen, and Dhillon (2012) reported a case study at Yunnan Agricultural University that explored ways to change students' approach to learning by encouraging them to adopt a deep approach to learning in developing their reading skills in English. After a four month training approach, a comparison of student test scores, showed that the $3 \mathrm{P}$ model of teaching and learning is suitable for developing the reading skills of students who are non- English majors, helping them to adopt a deep approach to learning in their reading through taking a deep approach to learning and changing attitudes and methods in teaching reading lectures can effectively foster the students' reading skills and improve their achievement.

Considering such work done so far to investigate the deep approach to learning in relation to English Language, the researcher inferred that: deep learning leads to a genuine understanding that 
promotes long-term retention of the learned material and, just as important, the ability to retrieve it and apply it to new problems in unfamiliar concepts. The use of small groups can result in greater academic achievement, more favorable attitudes, and increased persistence; the deep approach to learning leads from an intention to understand, to active conceptual analysis and if carried out thoroughly, generally result in a deep level of understanding. This approach is related to high quality learning outcomes; and students who use the deep approach to learning can transfer the learned concepts to a variety of situations by that means creating a denser matrix of connections within their knowledge and understanding.

All previous studies such as: Chen \& Dhillon (2012); Hermida (2009); Noor (2006); and Noor (2010); indicated the effectiveness of deep approach to learning in developing academic reading skills. So the researcher inferred the following conclusions: research on reading strategies has found that students who are better in their language performance generally make frequent use of a greater number of reading strategies and process reading materials at a deep level for greater reading comprehension. In addition, the deep approach proved to provide a tool for students' personal assessment and reflection as well as a comprehensive model for teachers and researchers. A student who is taking a deep approach reads widely, discusses with others, theorizes about the subjects, and relates what is learnt to personally meaningful context and existing prior knowledge. The deep approach to learning may provide a useful framework for developing EFL academic reading skills and writing skills.

\section{Context of the problem}

In spite of the importance of EFL higher-order reading skills in English Language, there is lack in these skills among engineering students as they are unprepared for academic reading skills demands placed upon them in higher-learning and they encounter difficulties. That 
is because of the shortcomings of school learning. To gain good marks, these learners concentrate on answering comprehension questions of which they have been rigorously taught to do by their teachers in school.

Some studies such as Shehata (2006); and Zaza (2001) stated that college students have problems in academic reading skills. They were not trained to understand and deal with long academic texts which are written for native speakers of the language or for people who have good command of the language, and so, they couldn't achieve their reading objectives.

\section{Statement of the Problem}

The problem of the study is identified in the weakness of first year students at Faculty of Engineering in their skills. To investigate such a problem, the present study attempts to answer the following question:

What is the effectiveness of using "Deep Approach to Learning" in developing EFL higher-order reading skills?

\section{Delimitations of the study}

1- A participants of first year Faculty of Engineering students for these reasons:

a) They lack academic reading skills. As in their secondary education, they were not trained to acquire these skills.

b) They need to develop proficiency in academic reading skills on relevant subject issues.

2- Some higher-order reading skills (CARS) required for first year Faculty of Engineering students (Appendix A).

\section{Research Methodology}

This study used the quantitative and qualitative methods to explore and investigate the effectiveness of "Deep Approach to Learning" in developing EFL higher-order reading skills. 


\section{The Participants of the Study}

The present study utilized the experimental design known as the Pre-Posttest Experimental \& Control Group Design. The participants of the present study were selected from first year students enrolled in Benha Faculty of Engineering during the first semester of the academic year 2016/2017. The study sample $(N=63)$ was divided into two groups: the experimental group $(\mathrm{N}=33)$ and the control group $(\mathrm{N}=30)$ students.

\section{Instruments of the Study}

Two academic reading skills tests were applied as a pre-test and a post-test. The two tests had different questions to measure the students' various higher-order reading skills (Appendix B).

\section{Implementation of the deep approach to learning}

After designing the test and the theory approach, the experimentation phase was administered as follows:

\section{- Pre- asessment}

Before implementing the approach, the researcher of the present study applied a pre-test to both the control group and the experimental group on $27^{\text {th }}$ September 2016, to make sure that both groups (experimental and control) are almost equivalent (homogenous). Moreover, the pre-test was used to determine the students' mastery level of EFL higher-order reading skills. The means, standard deviation and " $t$ " value of the two groups were computed.

Table (1): Findings of " $t$ " test between the control group and the experimental group in the pre-assessment of EFL higher-order reading skills

\begin{tabular}{|c|c|c|c|c|c|c|c||}
\hline Skill & Group & $\mathbf{N}$ & Mean & S.D & T-Value & D.F & Sig. \\
\hline \hline \multirow{2}{*}{$\begin{array}{c}\text { Higher-order } \\
\text { reading skills }\end{array}$} & Exp. & 33 & .5758 & 1.87133 & \multirow{2}{*}{0.620} & 61 & N.S. \\
\cline { 2 - 8 } & Cont. & 30 & .3333 & 1.09334 & & \\
\hline
\end{tabular}


Table (1) indicates that there are no significant differences between the mean scores of the two groups on the pre-assessment of the EFL higher-order reading skills, where " $t$ " value is $(0.620)$, which is not significant at (0.01) level of significance. This means that the two groups are equivalent in their pre-assessment of the vocabulary knowledge.

\section{- Treatment:}

To encourage students to participate in the "Deep Approach to Learning", the researcher attracted their interest by telling them that they would learn something new and interesting by using the Internet which is appealed to this generation and by working in groups. At the beginning of each session, the researcher used to set specific, attainable goals related to each part of the "Deep Approach to Learning" to increase students' motivation and their level of awareness and participation. The most active group was rewarded.

The approach was taught to the experimental group students $(n=33)$ by the researcher herself. The approach lasted for ten weeks with one session per week and each session lasted for 45 minutes. At the beginning of the sessions, the researcher introduced to the students what they are going to do. First, she told the students about the objectives of the approach and what they are supposed to gain as a result of their participation. After that she told them about the importance of EFL higher-order reading skills in general and for their academic study and work in particular. At the beginning of each session she told students the objectives of the session, the researcher's role, the student's role, the instructional materials that will be used, the activities they will perform, and ways of evaluating their progress and making sure that they achieve objectives of the sessions. At the end of the each session the researcher gave students some activities (team work, summarize and explain, concept map, and the amazing race) to what they had learned in order to be sure that they mastered the skills in each session. 
- Post-assessment

After the experimental treatment, the post-test was administered to the participants (experimental \& control groups) on 5th January, 2017.

\section{Findings of the study}

To find out whether there were significant differences in the EFL higher-order reading skills between the pre-test and the post-test of the study sample, all the data were statistically treated using t-test (Statistical Package for The Social Science SPSS, version 18). Furthermore, to assess the effect size of the treatment, Eta square formula $\left(\mathrm{y}^{2}\right)$ was used. (Abou-Hatab \& Sadek, 2010:441)

After applying the "Deep Approach to Learning", it was found out that, "There is a statistically significant difference between the mean scores of the experimental group and those of the control group students in "higherorder reading skills" in the post-test, in favor of the experimental group".

Table (2) presents the student's mean scores, standard deviations, $\mathrm{t}$-value and level of significance of both experimental and control group in the post-test in EFL higher-order reading skills.

Table (2): Findings of "t-test" between the mean scores of the experimental group and the control group students in the post-test in EFL higher-order reading skills.

\begin{tabular}{|c|c|c|c|c|c|c|c||}
\hline Skills & Group & $\mathbf{N}$ & Mean & S.D. & T-Value & D.F. & Sig. \\
\hline \hline $\begin{array}{c}\text { Application of } \\
\text { Academic Reading } \\
\text { Skills }\end{array}$ & Exp. & 33 & 9.2727 & 1.54662 & & & \\
\cline { 2 - 7 } & Cont. & 30 & 2.5333 & 1.59164 & 17.036 & 61 & 0.00 \\
\hline
\end{tabular}

Table (2) shows that there are statistically significant differences between the mean scores of the experimental group and the control group students in EFL higher-order reading skills in the post-test, in favor of the experimental group, where "t-value" is (17.04) which is 
significant at the (0.01) level of significance. Thus, the hypothesis was supported. Moreover, Eta square formula $\left(\mathrm{y}^{2}\right)$ of vocabulary knowledge is 0.83 , so the percentage of the effectiveness of constructive alignment theory in developing vocabulary knowledge is $83 \%$.

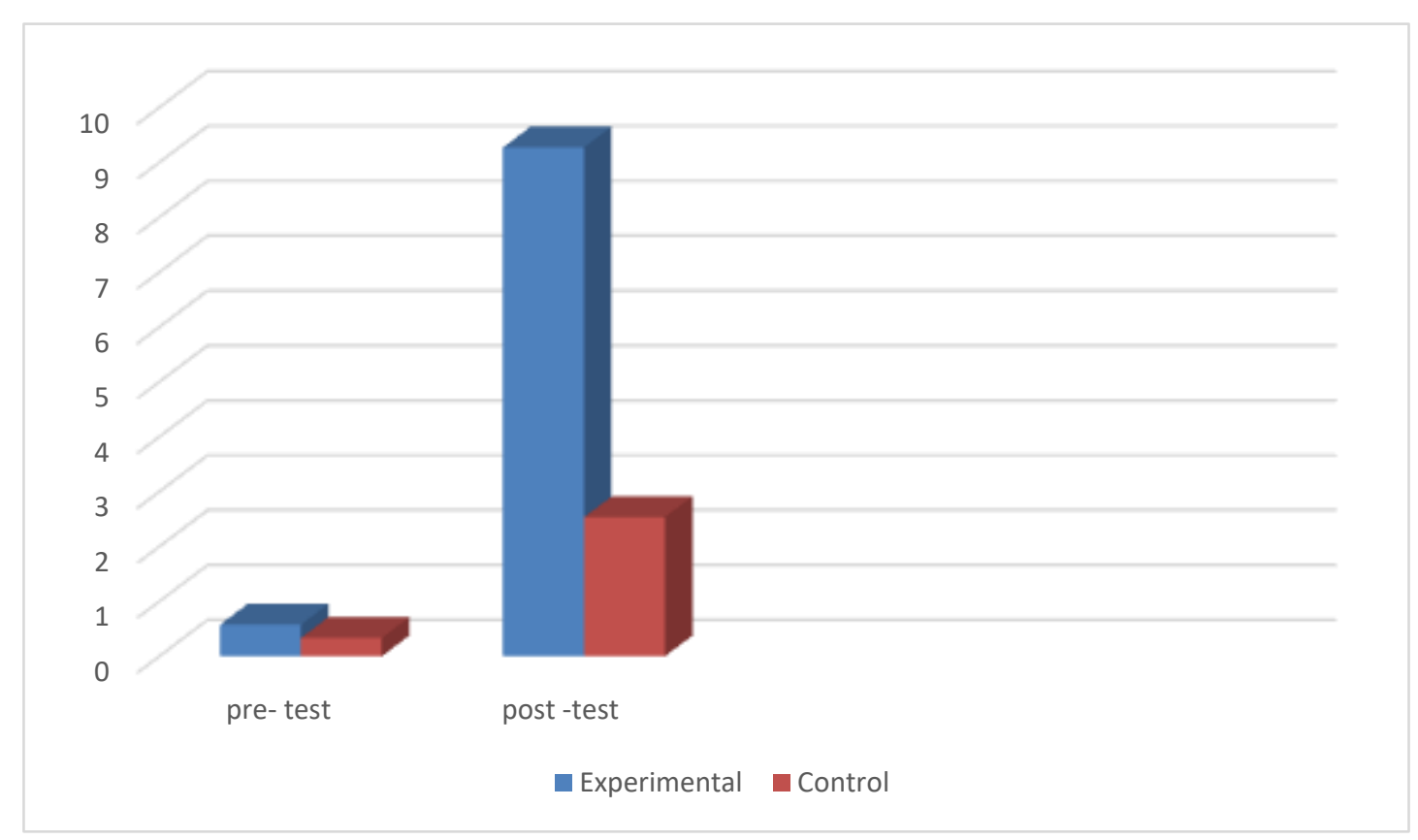

Figure (1):The mean scores of the control group and the experimental group in EFL higher-order reading skills

This result may be due to the activities used the "Deep Approach to Learning" such as: group work, team work, summarize and explain, concept map, and the amazing race. These activities helped students to improve their EFL higher-order reading skills and its performance indicators (Critique particular texts and compare them to other texts; and Synthesize and integrate material).

The researcher first modeled these activities in front of the students. Then she divided the students into small groups and began to practice the previous activities with her guidance. After that students began to apply the activities themselves. Thus, this training helped the students to master the skills. Students read the academic text and in 
groups they were divided into teams and they began the amazing race by getting to the internet with their smart phones and get more information about the basic idea in the academic text. They also represented their understanding of the text by producing graphs which display the relationships between concepts and ideas. They also were able to develop interrelations, create meaning schemes, and connect their previous knowledge with the new contexts which evaluated their progress in their higher-order reading skills.

\section{Eonclusion}

Based on the results of the statistically analysis of the data, it can be concluded that the experimental group students' EFL higher-order reading skills were developed as a result of using "Deep Approach to Learning" compared with the control group students who were taught through the regular method. This means that the "Deep Approach to Learning" is effective in achieving the aim of the present study.

The effectiveness of the "Deep Approach to Learning" may be due to the various activities and tasks that the researcher presented to the students.

\section{Recommendations of the study}

In the light of the findings, the following recommendations could be presented:

1- Teachers should pay attention to the development of the students' academic reading skills in the secondary stages, because EFL adult learners' academic reading problems are better solved out at this stage.

2- Teachers should pay attention to the learner-centered approach which helps the learners to control their own learning.

3- Teachers should give more focus on group and team work activities that allow students to interact with each other.

4- Training teachers of English language on the use of deep approach to learning steps while teaching English to their students. 
5- Teachers should teach students how to use the deep approach in academic reading texts in order to develop their reading comprehension skills through modeling the approach.

6- Material designers have to be cautious about the appropriateness of selected academic texts and the language materials to the students' levels and interests.

7- EFL curriculum designers should pay more attention to extensive reading practice.

8- EFL curriculum designers should make use of the deep approach when designing English language course.

9- Educational programs should include the training on the use of the deep approach in all courses.

\section{Suggestions for Further Research}

In the light of the findings of the present study, the following further researcher's suggestions were recommended to be investigated:

1- Investigating the effectiveness of deep approach to learning in developing learners' performance in the four skills of the English language.

2- Investigating learners' English academic reading problems and difficulties.

3- Developing the effect of reading programs for solving Learners' problems in academic reading skills.

4- Investigating the effect of using multimedia and new technologies to promote English academic reading skills at different levels. 


\section{References}

Alemi, Minoo, \& Ebadi, Saman (2010). The effects of pre-reading activities on ESP reading comprehension. Journal of Language Teaching and Research, 1(5), $569-577$.

Alyousef, Hesham (2005). Teaching reading comprehension to ESL/EFL learners. Reading Matrix, 5(2), 143-154.

Aryusmar (2013). The implication of pragmatic meaning comprehension in teaching ESP reading skills. $3^{\text {rd }}$ International Conference on Foreign Language Learning and Teaching, 2(1), 689 - 697.

Biggs, John (2003). Teaching for quality learning at university. The society for Research into Higher Education and Open University Press: Buckingham, U.K.

Chen, Liping \& Dhillon, Jaswinder K. (2012). Deep approaches to learning in improving reading skills: A case study from Yunnan Agriculture University. Theory and Practice in Language Studies, 2 (8), 1603 - 1613.

Cope, Chris (2003). Educationally critical characteristics of deep approaches to learning about the concept of an information system. Journal of Information Technology Education, 2, 415 - 427.

Erfani, Seyyed, Iranmehr, Abutaleb, \& Davari, Hossein (2011). Deepening ESP reading comprehension through visualization. Journal of Language Teaching and Research, 2(1), 270 - 275.

Fenwick, List, Humphrey, Sally, Quinn, Marie \& Endicott, Michele (2013). Developing deep understanding about language in undergraduate pre-service teacher approachs through the application of knowledge. Australian Journal of Teacher Education, 39(1), 1 - 38.

Field, John (2003). Psycholinguistics:A resource book for students. Great Britain: Routledge. 
Hellekjær, Glenn (2009). Academic English reading proficiency at the university level: a Norwegian case study. Reading in Foreign Language, 21(2), 198 - 222.

Hermida, Julian (2009). The importance of teaching academic reading skills in first- year university course. The International Journal of Research and Review, 3, 20 - 30.

Hermida, Julian (2010) Strategies to promote a deep approach to reading. Retrieved from http://www.trincoll.edu/nr/rdonlyers. (retrieved on: 15-11-2010)

Hyland, Ken (2007). English for Specific Purposes: Some Influences and Impacts. In Cummins, Jim \& Davison, Chris (Eds.), International Handbook of English Language Teaching (pp. 379 - 390) .USA, New York: Springer.

Karaman, Cendel, Ökten, Celile \& Tochon, Francois (2012). Learning the deep approach: Language teachers' voices. Porta Linguarum, $18,79-95$.

Levine, Adina; Ferenz, Orna; and Reves, Thea (2000). EFL academic reading skills and modern technology: How can we turn our students into independent critical readers? TESL-EJ, 4(4), $1-12$.

Lublin, Jackie (2003). Deep, surface and strategic approaches to learning. A paper presented at Center for Teaching and Learning. Retrieved from http://www.itu.qut.edu.au/development/curriculumde. (retrieved on: 15-10-2010)

Millis, Barbara J. (2002). Enhancing learning - and more! - Through cooperative learning. Paper (38) presented at IDEA Center, Manhattan, Kansas.

Millis, Barbara J. (2010). Promoting deep learning. Paper (47) presented at IDEA Center, Manhattan, Kansas. 
Mohanna, Kay (2008). The all - round flexible and adoptable teacher. In Mohanna, Chambers \& Wall (Eds.), Your teaching style: A practical guide to understanding, developing, and improving (pp. 23 - 30). New York, Radcliffe Publishing Ltd.

Mohd., Noor (2006). Reading academic text: Awareness and experiences among university ESL learners. GEMA Online Journal of Language Studies, 6(2), 65 - 77.

Noor, Noorizah Mohd (2006). Reading academic text: Awareness and experiences among university ESL learners. GEMA Online Journal of Language Studies, 6(2), 65 - 78.

Noor, Noorizah Mohd (2007). Reading an academic expository text - the ESL learner's Experience. Retrieved from http://repo.uum.edu.my/3262/1/N4.pdf. (retrieved on: 20-4-2016)

Noor, Noorizah Mohd (2010). ESL learners' reading approaches of an academic expository text. $3 L$ The Southeast Asian Journal of English Language Studies, 16 (2), 19 - 46.

Rahman, Md. (2012). The English language needs of computer science undergraduate students at Putra University, Malaysia: A focus on reading skills. English for Specific Purposes World, 12(34), 1- 25.

Rao, Zhenhui, Gu, Peter Yongqi, Zhang, Lawrence Jun \& Hu,Guangwei (2007). Approaches to learning and reading strategy use of bilingual primary school pupils. Language Awareness, 16(4), 243 - 262.

Shehata, Mohammad Abdel - Ghany M. (2006). The Effectiveness of Semantic Mapping Strategy and DRTA Strategy in Developing Benha High Institute of Technology Students' Reading Comprehension Skills. (Unpublished M. Ed.Thesis), Faculty of Education, Benha University, Egypt. 
Smith, Colin A. (2005). How useful are concepts of learning approaches to thinking about early professional learning? Paper presented at Contribution to EPL Project Mini Conference, Stirling University.

Smith, M cecil (1993). Changing reading ability and attitudes from childhood to adulthood: A life span perspective. In Yussen, Steven \& Smith, M Cecil (Eds.), Reading across the life span, (pp. 273291). New York, Springer.

Surgenor, Paul (2010) Constructive alignment. Retrieved from http://www.ucd.ie/teaching. (retrieved on: 25-2-2011)

Syatriana, Eny (2013). Developing the students, reading comprehension through cognitive reading strategies of the first year students of SMAN 16 Makassar. Retrieved from: http://www.niu.edu/international/images/Eny\%20syatriana.pdf. (retrieved on: 5- 9- 2015)

Tabatabaei, Omid, \& Assari, Fahimeh (2011). Investigating strategic processes of L2 reading comprehension among Collegiate Iranian ESP learners across three academic fields of study. Canadian Social Science, 7(5), 205 - 214.

Tam, Maureen (1999). Promoting Deep learning: A conceptual Model. Retrieved from http://www.in.edu.hk/tlc/learning-matters. (retrieved on: 23-10-2010)

Tochon, Francois (2010). Deep education. Journal forEducation, Teachers and Trainers JETT, 1, 1- 12.

Tochon, Francois (2013). Effectiveness of deep, blended language learning as measured by oral proficiency and course evaluation. Journal of The National Council of Less Commonly Taught Languages, 14, $51-86$.

Tochon, Francois (2014). Blended technologies for a deep approach to foreign language teaching and learning. Paper presented at Foreign Languages and International Integration, University of Hanoi. 
Xiao, Jianfang (2015). Deep approach to world languages and cultures learning. International Journal of Innovation and Research in Educational Sciences, 2(6), 2349 - 5219.

Yong, Fung Lan (2010). A study on the learning Approaches of Malaysian students in relation to English language acquisition. American Journal of Scientific Research, 9, 5-11.

Yüce, Erkan; Tarakçioğlu, Asli Özlem (2013). Attitudes of computer engineering department students towards ESP courses integrated to foreign language courses: Tunceli University Case. Bilim ve Gençlik Dergisi, 1 (1), 47-57.

Zaza, Mona Salem (2001). Developing metacognitive strategies and determining their effect on the academic reading skills of freshmen students of the English section in Faculties of Education (Unpublished Doctoral dissertation). Benha University, Benha.

ابو حطب، فؤاد وصادق، أمال (· ( · ): مناهج البحث وطرق التحليل الإحصائي (في العلوم النفسية والتربوية والإجتماعية). القاهرة: مكتبة الانجلو المصرية. 


\section{Appendix A}

\section{Higher-order reading skills Checklist}

Not appropriate 0 Appropriate 1

Important to some extent 2 Important 3

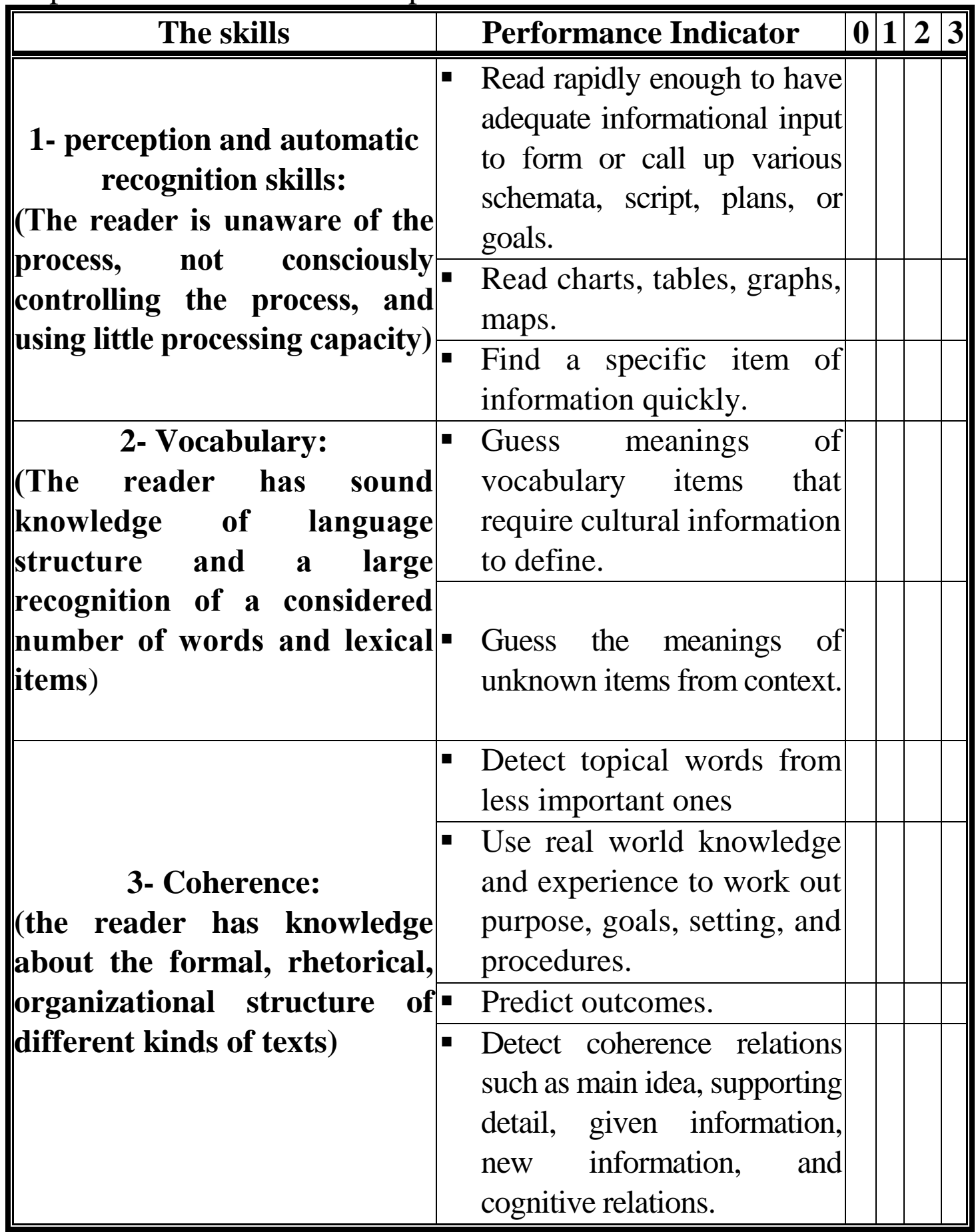




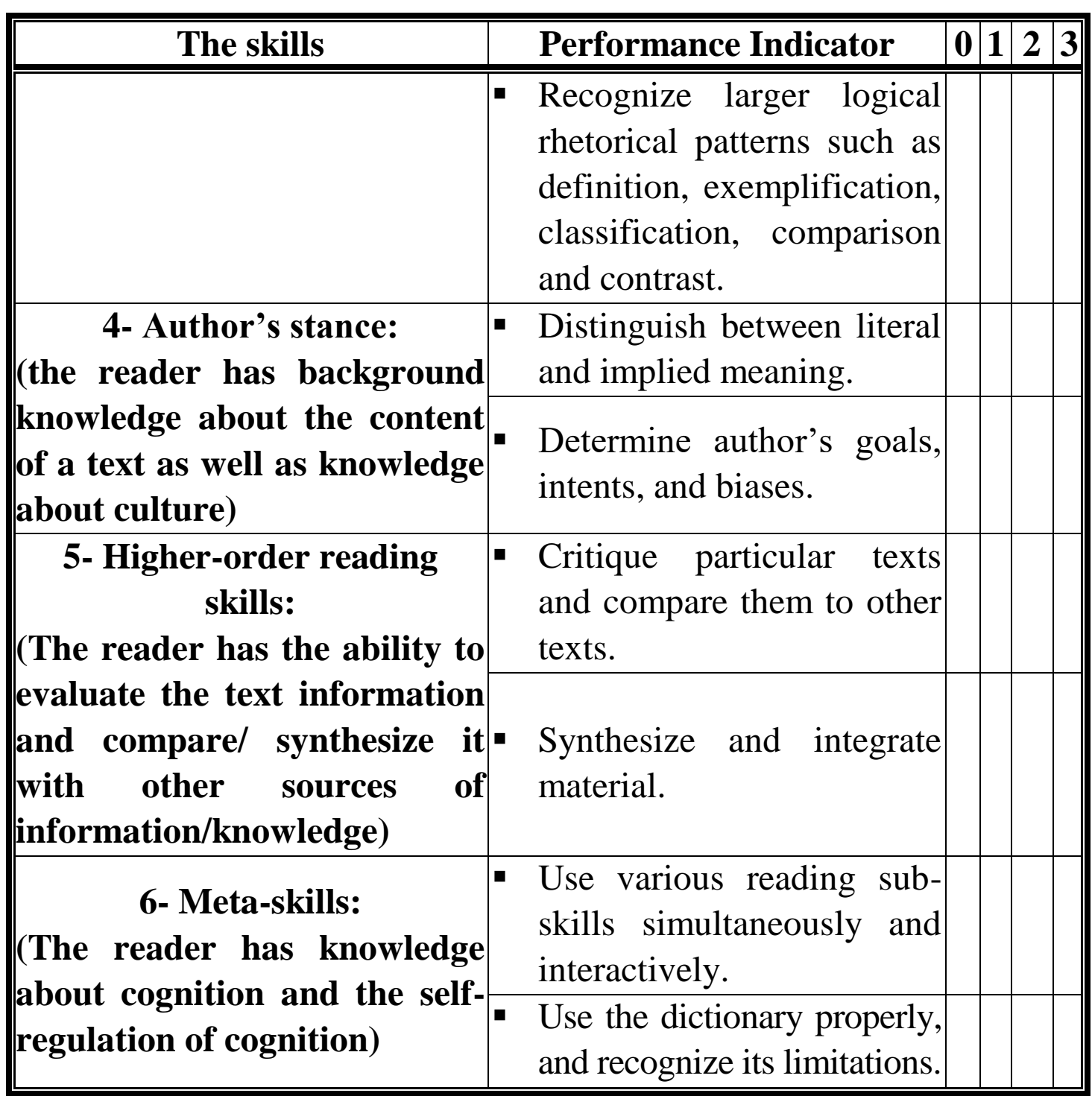




\section{Appendix B}

\section{The reading pre-test}

\section{PAPER RECYCLING}

(Source: http://www.ielts-mentor.com/reading-sample/academicreading/34-ielts-academic-reading-sample-9-paper-recycling)

a) Paper is different from other waste produce because it comes from a sustainable resource: trees. Unlike the minerals and oil used to make plastics and metals, trees are replaceable. Paper is also biodegradable, so it does not pose as much threat to the environment when it is discarded. While 45 out of every 100 tonnes of wood fibre used to make paper in Australia comes from waste paper, the rest comes directly from virgin fibre from forests and plantations. By world standards, this is a good performance since the worldwide average is 33 percent waste paper. Governments have encouraged waste paper collection and sorting schemes and at the same time, the paper industry has responded by developing new recycling technologies that have paved the way for even greater utilization of used fibre. As a result, industry's use of recycled fibres is expected to increase at twice the rate of virgin fibre over the coming years.

b) Already, waste paper constitutes $70 \%$ of paper used for packaging and advances in the technology required to remove ink from the paper have allowed a higher recycled content in newsprint and writing paper. To achieve the benefits of recycling, the community must also contribute. We need to accept a change in the quality of paper products; for example, stationery may be less white and of a rougher texture. There also needs to support from the community for waste paper collection programs. Not only do we need to make the paper available to collectors but it also needs to be separated into different types and sorted from contaminants such as staples, paperclips, string and other miscellaneous items. 
c) There are technical limitations to the amount of paper which can be recycled and some paper products cannot be collected for re-use. These include paper in the form of books and permanent records, photographic paper and paper which is badly contaminated. The four most common sources of paper for recycling are factories and retail stores which gather large amounts of packaging material in which goods are delivered, also offices which have unwanted business documents and computer output, paper converters and printers and lastly households which discard newspapers and packaging material. The paper manufacturer pays a price for the paper and may also incur the collection cost.

d) Once collected, the paper has to be sorted by hand by people trained to recognise various types of paper. This is necessary because some types of paper can only be made from particular kinds of recycled fibre. The sorted paper then has to be repulped or mixed with water and broken down into its individual fibres. This mixture is called stock and may contain a wide variety of contaminating materials, particularly if it is made from mixed waste paper which has had little sorting. Various machineries are used to remove other materials from the stock. After passing through the repulping process, the fibres from printed waste paper are grey in colour because the printing ink has soaked into the individual fibres. This recycled material can only be used in products where the grey colour does not matter, such as cardboard boxes but if the grey colour is not acceptable, the fibres must be de-inked. This involves adding chemicals such as caustic soda or other alkalis, soaps and detergents, water-hardening agents such as calcium chloride, frothing agents and bleaching agents. Before the recycled fibres can be made into paper they must be refined or treated in such a way that they bond together. 
e) Most paper products must contain some virgin fibre as well as recycled fibres and unlike glass, paper cannot be recycled indefinitely. Most paper is down-cycled which means that a product made from recycled paper is of an inferior quality to the original paper. Recycling paper is beneficial in that it saves some of the energy, labour and capital that go into producing virgin pulp. However, recycling requires the use of fossil fuel, a nonrenewable energy source, to collect the waste paper from the community and to process it to produce new paper. And the recycling process still creates emissions which require treatment before they can be disposed of safely. Nevertheless, paper recycling is an important economical and environmental practice but one which must be carried out in a rational and viable manner for it to be useful to both industry and the community.

\section{Questions 1-7}

Complete the summary below of the first two paragraphs of the Reading Passage.

Choose ONE OR TWO WORDS from the Reading Passage for each answer.

Write your answers in boxes 30-36 on your answer sheet.

\section{SUMmary}

\section{Example ....}

From the point of view of recycling, paper has two advantages over minerals and in that firstly it comes from a resource which is and secondly, it is less threatening to our environment when we throw it away because it is (2) ...... Although Australia's record in the re-use of waste paper is good, it is still necessary to use a combination of recycled fibre and (3) to make new paper. The paper industry has 
contributed positively and people have also been encouraged by to collect their waste on a regular basis. One major difficulty is the removal of ink from used paper but are being made in this area. However, we need to learn to accept paper which is generally of a lower ......... (6) ......... than before and to sort our waste paper by removing (7) ......... before discarding it for collection.

Look at paragraphs $\mathrm{C}, \mathrm{D}$, and $\mathrm{E}$ and, using the information in the passage, complete the flow chart below. Write your answers in boxes 812 on your answer sheet. Use ONE OR TWO WORDS for each answer.

- Waste Paper collected from: Factories, Retail stores, ...(8)..., Paper converted and printers, Households.

- The Paper is then .....(9)..... and ....(10).....by adding water. Chemicals are added in order to ....(11).... The fibers are then ...(12)......

\section{The second passage: AIRPORTS ON WATER}

(Source: http://www.ielts-mentor.com/reading-sample/academicreading/794-ielts-academic-reading-sample-124-airports-on-water)

River deltas are difficult places for map makers. The river builds them up, the sea wears them down; their outlines are always changing. The changes in China's Pearl River delta, however, are more dramatic than these natural fluctuations. An island six kilometers long and with a total area of 1248 hectares is being created there. And the civil engineers are as interested in performance as in speed and size. This is a bit of the delta that they want to endure.

The new island of Chek Lap Kok, the site of Hong Kong's new airport, is $83 \%$ complete. The giant dumper trucks rumbling across it will have finished their job by the middle of this year and the airport itself will be built at a similarly breakneck pace. 
As Chek Lap Kok rises, however, another new Asian island is sinking back into the sea. This is a 520-hectare island built in Osaka Bay, Japan, that serves as the platform for the new Kansai airport. Chek Lap Kok was built in a different way, and thus hopes to avoid the same sinking fate.

The usual way to reclaim land is to pile sand rock on to the seabed. When the seabed oozes with mud, this is rather like placing a textbook on a wet sponge: the weight squeezes the water out, causing both water and sponge to settle lower. The settlement is rarely even: different parts sink at different rates. So buildings, pipes, roads and so on tend to buckle and crack. You can engineer around these problems, or you can engineer them out. Kansai took the first approach; Chek Lap Kok is taking the second.

The differences are both political and geological. Kansai was supposed to be built just one kilometer offshore, where the seabed is quite solid. Fishermen protested, and the site was shifted a further five kilometers. That put it in deeper water (around 20 meters) and above a seabed that consisted of 20 meters of soft alluvial silt and mud deposits. Worse, below it was a not-very- firm glacial deposit hundreds of meters thick.

The Kansai builders recognized that settlement was inevitable. Sand was driven into the seabed to strengthen it before the landfill was piled on top, in an attempt to slow the process; but this has not been as effective as had been hoped. To cope with settlement, Kansai's giant terminal is supported on 900 pillars. Each of them can be individually jacked up, allowing wedges to be added underneath. That is meant to keep the building level. But it could be a tricky task.

Conditions are different at Chek Lap Kok. There was some land there to begin with, the original little island of Chek Lap Kok and a smaller outcrop called Lam Chau. Between them, these two outcrops of hard, weathered granite make up a quarter of the new island's surface area. Unfortunately, between the islands there was a layer of soft mud, 27 meters thick in places. 
According to Frans Uiterwijk, a Dutchman who is the project's reclamation director, it would have been possible to leave this mud below the reclaimed land, and to deal with the resulting settlement by the Kansai method. But the consortium that won the contract for the island opted for a more aggressive approach. It assembled the worlds largest fleet of dredgers, which sucked up $150 \mathrm{~m}$ cubic meters of clay and mud and dumped it in deeper waters. At the same time, sand was dredged from the waters and piled on top of the layer of stiff clay that the massive dredging had laid bare.

Nor was the sand the only thing used. The original granite island which had hills up to 120 meters high was drilled and blasted into boulders no bigger than two meters in diameter. This provided $70 \mathrm{~m}$ cubic meters of granite to add to the island's foundations. Because the heap of boulders does not fill the space perfectly, this represents the equivalent of $105 \mathrm{~m}$ cubic meters of landfill. Most of the rock will become the foundations for the airport's runways and its taxiways. The sand dredged from the waters will also be used to provide a two-meter capping layer over the granite platform. This makes it easier for utilities to dig trenches -granite is unyielding stuff. Most of the terminal buildings will be placed above the site of the existing island. Only a limited amount of pile-driving is needed to support building foundations above softer areas.

The completed island will be six to seven meters above sea level. In all, $350 \mathrm{~m}$ cubic meters of material will have been moved. And much of it, like the overloads, has to be moved several times before reaching its final resting place. For example, there has to be a motorway capable of carrying 150-tonne dump-trucks; and there has to be a raised area for the 15,000 construction workers. These are temporary; they will be removed when the airport is finished.

The airport, though, is here to stay. To protect it, the new coastline is being bolstered with a formidable twelve kilometers of sea defenses. The brunt of a typhoon will be deflected by the neighboring island of 
Lantau; the sea walls should guard against the rest. Gentler but more persistent bad weather - the downpours of the summer monsoon - is also being taken into account. A mat-like material called geo textile is being laid across the island to separate the rock and sand layers. That will stop sand particles from being washed into the rock voids, and so causing further settlement This island is being built never to be sunk.

\section{Questions 1-5}

Classify the following statements as applying to
a) Chek Lap Kok airport only
b) Kansai airport only
c) Both airports

Write the appropriate letters $\mathrm{A}-\mathrm{C}$ in boxes $1-5$ on your answer sheet Example Answer

built on a man-made island $\mathrm{C}$

1- having an area of over 1000 hectares

2- built in a river delta

3 - built in the open sea

4- built by reclaiming land

5- built using conventional methods of reclamation

\section{Questions 6-9}

\section{Complete the labels on Diagram B below.}

Choose your answers from the box below the diagram and write them in boxes 6-9 on your answer sheet.

$N B$ There are more words/phrases than spaces, so you will not use them all. 


\section{DIAGRAM A}

Cross-section of the original area around Chek Lap Kok before work began

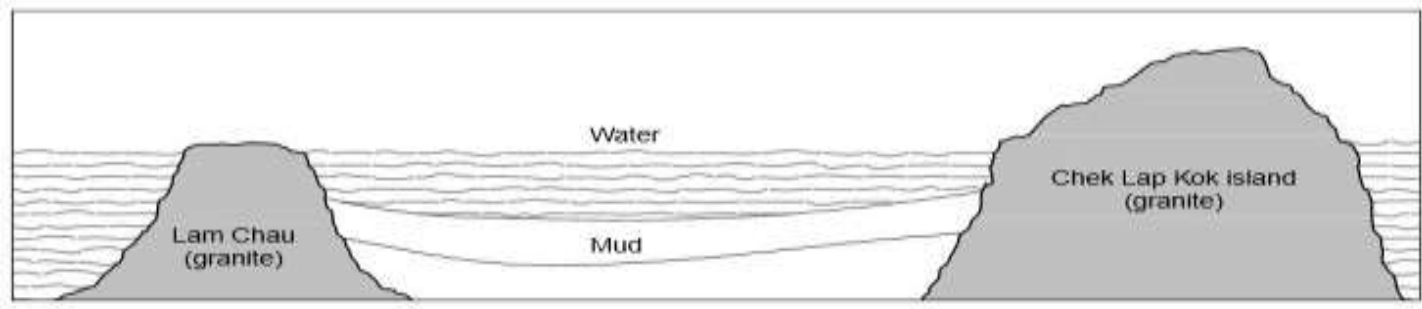

DIAGRAM B

Cross-section of the same area at the time the article was written

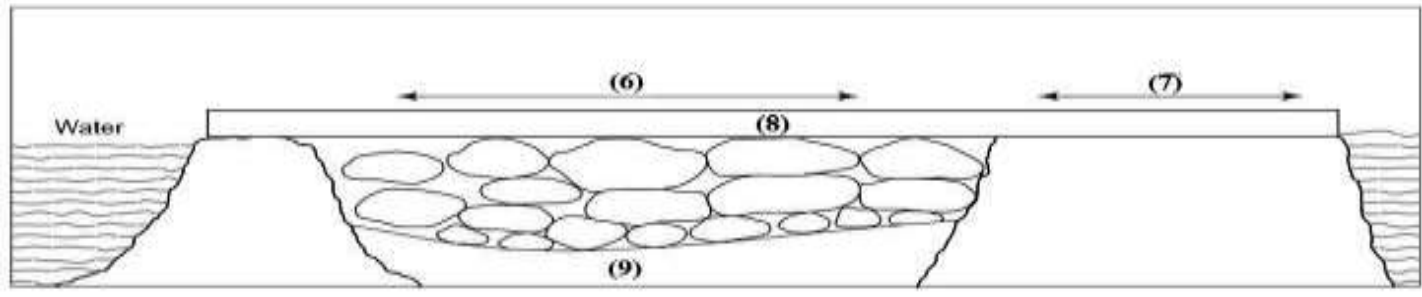

granite

mud

terminal building site

sand runways and taxiways

water

stiff clay

\section{Questions 10-13}

\section{Complete the summary below.}

Choose your answers from the box below the summary and write them in boxes $10-13$ on your answer sheet.

NB There are more words than spaces, so you will not use them all.

When the new Chek Lap Kok airport has been completed, the raised area and the .......... (Example) .......... will be removed. motorway The island will be partially protected from storms by .........(10)........ and also by (11) Further settlement caused by (12) will be prevented by the use of .(13).......... . 
[construction workers - coastline - dump-trucks - geotextile Lantau Island - motorway -rainfall - rock and sand - rock voids sea walls - typhoons]

\section{The reading post-test}

\section{The Academic Reading test is $\mathbf{4 0}$ minutes long.}

There are 2 sections. The total text length is $2,150-2,750$ words.

- Each section contains one long text.

- Texts are authentic

- Texts range from descriptive and factual to the discursive and analytical.

- Texts may contain non-verbal materials, such as diagrams, graphs or illustrations.

- If texts contain technical terms, a simple glossary is provided.

A variety of questions is used, chosen from the following types: multiple choice, identifying information, identifying writer's views/claims, matching information, matching headings, matching features, matching sentence endings, sentence completion, summary completion, note completion, table completion, flow-chart completion, diagram label completion, short-answer questions.

\section{The first passage:}

\section{THE ROCKET FROM EAST TO WEST}

(Source: http://www.ielts-mentor.com/reading-sample/academicreading/36-ielts-academic-reading-sample-11-the-rocket-from-east-to-west)

a) The concept of the rocket, or rather the mechanism behind the idea of propelling an object into the air, has been around for well over two thousand years. However, it wasn't until the discovery of the reaction principle, which was the key to space travel and so represents one of the great milestones in the history of scientific thought, that rocket technology was able to develop. Not only did it solve a problem that had intrigued man for ages, but, more importantly, it literally opened the door to the exploration of the universe. 
b) An intellectual breakthrough, brilliant though it may be, does not automatically ensure that the transition is made from theory to practice. Despite the fact that rockets had been used sporadically for several hundred years, they remained a relatively minor artefact of civilization until the twentieth century. Prodigious efforts, accelerated during two world wars, were required before the technology of primitive rocketry could be translated into the reality of sophisticated astronauts. It is strange that the rocket was generally ignored by writers of fiction to transport their heroes to mysterious realms beyond the Earth, even though it had been commonly used in fireworks displays in China since the thirteenth century. The reason is that nobody associated the reaction principle with the idea of traveling through space to a neighbouring world.

c) A simple analogy can help us to understand how a rocket operates. It is much like a machine gun mounted on the rear of a boat. In reaction to the backward discharge of bullets, the gun, and hence the boat, move forwards. A rocket motor's 'bullets' are minute, high-speed particles produced by burning propellants in a suitable chamber. The reaction to the ejection of these small particles causes the rocket to move forwards. There is evidence that the reaction principle was applied practically well before the rocket was invented. In his Noctes Atticae or Greek Nights, Aulus Gellius describes 'the pigeon of Archytas', an invention dating back to about 360 BC. Cylindrical in shape, made of wood, and hanging from string, it was moved to and fro by steam blowing out from small exhaust ports at either end. The reaction to the discharging steam provided the bird with motive power.

d) The invention of rockets is linked inextricably with the invention of 'black powder'. Most historians of technology credit the Chinese with its discovery. They base their belief on studies of Chinese writings or on the notebooks of early Europeans who 
settled in or made long visits to China to study its history and civilisation. It is probable that, sometime in the tenth century, black powder was first compounded from its basic ingredients of saltpetre, charcoal and sulphur. But this does not mean that it was immediately used to propel rockets. By the thirteenth century, powder propelled fire arrows had become rather common. The Chinese relied on this type of technological development to produce incendiary projectiles of many sorts, explosive grenades and possibly cannons to repel their enemies. One such weapon was the 'basket of fire' or, as directly translated from Chinese, the 'arrows like flying leopards'. The 0.7 metre-long arrows, each with a long tube of gunpowder attached near the point of each arrow, could be fired from a long, octagonal-shaped basket at the same time and had a range of 400 paces. Another weapon was the 'arrow as am flying sabre', which could be fired from crossbows. The rocket, placed in a similar position to other rocket-propelled arrows, was designed to increase the range. A small iron weight was attached to the $1.5 \mathrm{~m}$ bamboo shaft, just below the feathers, to increase the arrow's stability by moving the centre of gravity to a position below the rocket. At a similar time, the Arabs had developed the 'egg which moves and burns'. This 'egg' was apparently full of gunpowder and stabilised by a $1.5 \mathrm{~m}$ tail. It was fired using two rockets attached to either side of this tail.

e) It was not until the eighteenth century that Europe became seriously interested in the possibilities of using the rocket itself as a weapon of war and not just to propel other weapons. Prior to this, rockets were used only in pyrotechnic displays. The incentive for the more aggressive use of rockets came not from within the European continent but from far-away India, whose leaders had built up a corps of rocketeers and used rockets successfully against 
the British in the late eighteenth century. The Indian rockets used against the British were described by a British Captain serving in India as 'an iron envelope about 200 millimetres long and 40 millimetres in diameter with sharp points at the top and a 3m-long bamboo guiding stick'. In the early nineteenth century, the British began to experiment with incendiary barrage rockets. The British rocket differed from the Indian version in that it was completely encased in a stout, iron cylinder, terminating in a conical head, measuring one metre in diameter and having a stick almost five metres long and constructed in such a way that it could be firmly attached to the body of the rocket. The Americans developed a rocket, complete with its own launcher, to use against the Mexicans in the mid-nineteenth century. A long cylindrical tube was propped up by two sticks and fastened to the top of the launcher, thereby allowing the rockets to be inserted and lit from the other end. However, the results were sometimes not that impressive as the behaviour of the rockets in flight was less than predictable. Since then, there have been huge developments in rocket technology, often with devastating results in the forum of war. Nevertheless, the modern day space programs owe their success to the humble beginnings of those in previous centuries who developed the foundations of the reaction principle. Who knows what it will be like in the future?

\section{Questions 1-4}

Choose the most suitable headings for paragraphs $\boldsymbol{B}-\boldsymbol{E}$ from the list of headings below.

Write the appropriate numbers (i-ix) in boxes 1-4 on your answer sheet. 


\section{List of Headings}

How the reaction principle works

The impact of the reaction principle

Writer's theories of the reaction principle

Undeveloped for centuries

The first rockets

The first use of steam

Rockets for military use

Developments of fire

What's next?

\section{Example Paragraph A Answer ii}

1- Paragraph B

2- Paragraph $\mathbf{C}$

3- Paragraph D

4- Paragraph $\mathbf{E}$

\section{Questions 5 and 6}

Choose the appropriate letters A-D and write them in boxes 5 and 6 on your answer sheet.

5- The greatest outcome of the discovery of the reaction principle was that

a) rockets could be propelled into the air.

b) space travel became a reality.

c) a major problem had been solved.

d) bigger rockets were able to be built.

6- According to the text, the greatest progress in rocket technology was made 
a) from the tenth to the thirteenth centuries.

b) from the seventeenth to the nineteenth centuries.

c) from the early nineteenth to the late nineteenth century.

d) from the late nineteenth century to the present day.

\section{Questions 7-10}

From the information in the text, indicate who FIRST invented or used the items in the list below.

Write the appropriate letters A-E in boxes 7-10 on your answer sheet.

NB You may use any letter more than once.

\section{Example}

rockets for displays
Answer

A

7- black powder

8- rocket-propelled arrows for fighting

9- rockets as war weapons

10- the rocket launcher
a) the Chinese
b) the Indians
c) the British
d) the Arabs
e) the Americans

FIRST invented or used by

\section{Questions 11-14}

Look at the drawings of different projectiles below, $\boldsymbol{A}-\boldsymbol{H}$, and the names of types of projectiles given

in the passage, Questions 11-14. Match each name with one drawing.

Write the appropriate letters $\boldsymbol{A}-\boldsymbol{H}$ in boxes 11-14 on your answer sheet.

Example

The Greek 'pigeon of Archytas'

11- The Chinese 'basket of fire'

\section{Answer}

C 
12- The Arab 'egg which moves and burns'

13- The Indian rocket

14- The British barrage rocket.

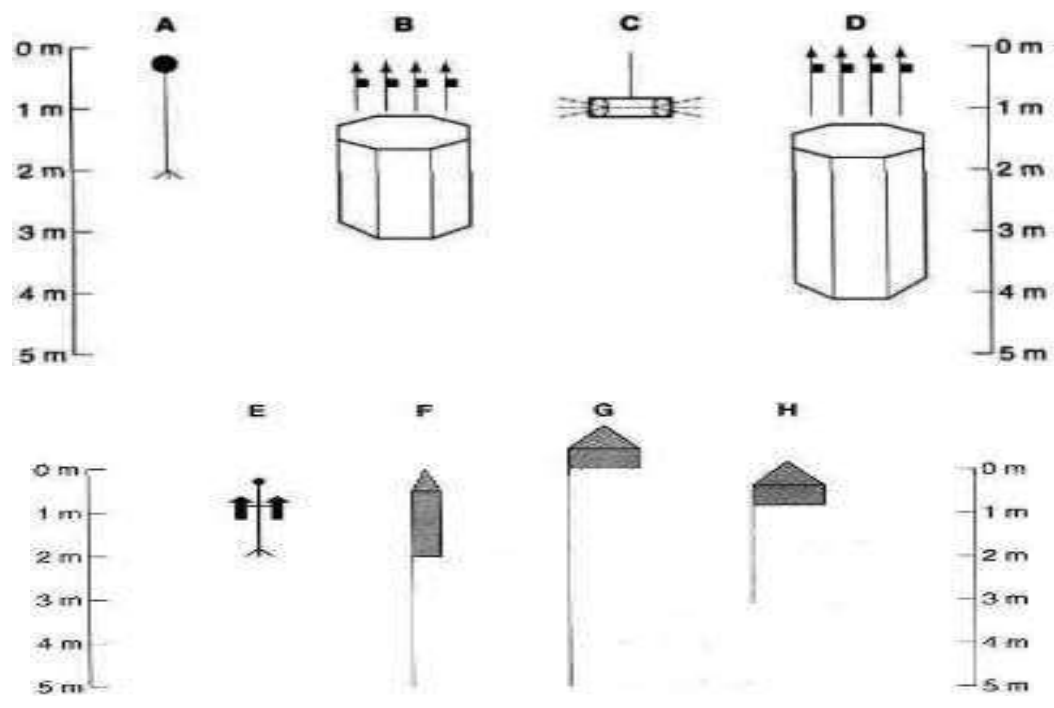

\section{The second passage:}

\section{CREATING ARTIFICIAL REEFS}

(Source: http://www.ielts-mentor.com/reading-sample/academicreading/44-ielts-academic-reading-sample-19-creating-artificial-reefs)

In the coastal waters of the US, a nation's leftovers have been discarded. Derelict ships, concrete blocks, scrapped cars, army tanks, tyres filled with concrete and redundant planes litter the sea floor. However, this is not waste disposal, but part of a coordinated, state-run programme. To recently arrived fish, plants and other sea organisms, these artificial reefs are an ideal home, offering food and shelter.

Sea-dumping incites widespread condemnation. Little surprise when oceans are seen as 'convenient' dumping grounds for the rubbish we have created but would rather forget. However, scientific evidence suggests that if we dump the right things, sea life can actually be enhanced. And more recently, purpose-built structures of steel or concrete have been employed - some the size of small apartment blocks principally to increase fish harvests. 
Strong currents, for example, the choice of design and materials for an artificial reef depends on where it is going to be placed. In areas of a solid concrete structure will be more appropriate than ballasted tyres. It also depends on what species are to be attracted. It is pointless creating high-rise structures for fish that prefer flat or low-relief habitat. But the most important consideration is the purpose of the reef.

In the US, where there is a national reef plan using cleaned up rigs and tanks, artificial reefs have mainly been used to attract fish for recreational fishing or sport-diving. But there are many other ways in which they can be used to manage the marine habitat. For as well as protecting existing habitat, providing purpose-built accommodation for commercial species (such as lobsters and octupi) and acting as sea defences, they can be an effective way of improving fish harvests.

Japan, for example, has created vast areas of artificial habitat rather than isolated reefs - to increase its fish stocks. In fact, the cultural and historical importance of seafood in Japan is reflected by the fact that it is a world leader in reef technology; what's more, those who construct and deploy reefs have sole rights to the harvest.

In Europe, artificial reefs have been mainly employed to protect habitat. Particularly so in the Mediterranean where reefs have been sunk as physical obstacles to stop illegal trawling, which is destroying sea grass beds and the marine life that depends on them. If you want to protect areas of the seabed, you need something that will stop trawlers dead in their tracks,' says Dr Antony Jensen of the Southampton Oceanography Centre.

Italy boasts considerable artificial reef activity. It deployed its first scientifically planned reef using concrete cubes assembled in pyramid forms in 1974 to enhance fisheries and stop trawling. And Spain has built nearly 50 reefs in its waters, mainly to discourage trawling and enhance the productivity of fisheries. Meanwhile, Britain established its first quarried rock artificial reef in 1984 off the Scottish coast, to assess its potential for attracting commercial species.

But while the scientific study of these structures is a little over a quarter of a century old, artificial reefs made out of readily available materials such as bamboo and coconuts have been used by fishermen for 
centuries. And the benefits have been enormous. By placing reefs close to home, fishermen can save time and fuel. But unless they are carefully managed, these areas can become over- fished. In the Philippines, for example, where artificial reef programmes have been instigated in response to declining fish populations, catches are often allowed to exceed the maximum potential new production of the artificial reef because there is no proper management control.

There is no doubt that artificial reefs have lots to offer. And while purpose-built structures are effective, the real challenge now is to develop environmentally safe ways of using recycled waste to increase marine diversity. This will require more scientific research. For example, the leachates from one of the most commonly used reef materials, tyres, could potentially be harmful to the creatures and plants that they are supposed to attract. Yet few extensive studies have been undertaken into the long- term effects of disposing of tyres at sea. And at the moment, there is little consensus about what is environmentally acceptable to dump at sea, especially when it comes to oil and gas rigs. Clearly, the challenge is to develop environmentally acceptable ways of disposing of our rubbish while enhancing marine life too. What we must never be allowed to do is have an excuse for dumping anything we like at sea.

\section{Questions 1-3}

The list below gives some of the factors that must be taken into account when deciding how to construct an artificial reef. Which THREE of these factors are mentioned by the writer of the article? Write the appropriate letters A-F in boxes 1-3 on your answer sheet.
A) The fishing activity in the area
B) The intended location of the reef
C) The existing reef structures
D) The type of marine life being targeted
E) The function of the reef
F) The cultural importance of the area 


\section{Questions 4-8}

Complete the table below. Choose NO MORE THAN THREE WORDS from the passage for each answer. Write your answers in boxes 4-8 on your answer sheet.

\begin{tabular}{||c|c|c|}
\hline \hline Area/Country & Type of Reef & Purpose \\
\hline \hline US & Made using old ....(4).... & $\begin{array}{c}\text { To attract fish for leisure } \\
\text { activities }\end{array}$ \\
\hline Japan & $\begin{array}{c}\text { Forms large area of } \\
\text { artificial habitat }\end{array}$ & to improve ....(5).... \\
\hline Europe & $\begin{array}{c}\text { lies deep down to } \\
\text { form ...(6)... }\end{array}$ & to act as a sea defence \\
\hline Italy & $\begin{array}{c}\text { Consists of pyramid } \\
\text { shapes of ....(7).... }\end{array}$ & to prevent trawling \\
\hline Britain & made of rock & $\begin{array}{c}\text { to encourage ....(8).... Fish } \\
\text { species }\end{array}$ \\
\hline
\end{tabular}

\section{Questions 9-12}

Using NO MORE THAN THREE WORDS, complete the following sentences. Write your answers in boxes 9-12 on your answer sheet.

In .....(9)....., people who build reefs are legally entitled to all the fish they attract. Trawling inhibits the development of marine life because it damages the .....(10)...... In the past, both ......(11).......were used to make reefs. To ensure that reefs are not over-fished, good ......(12)..... is required.

\section{Question 13}

Choose the appropriate letter A-D and write it in box 13 on your answer sheet.

13-According to the writer, the next step in the creation of artificial reefs is

A) to produce an international agreement.

B) to expand their use in the marine environment.

C) to examine their dangers to marine life.

D) to improve on purpose-built structures. 